\title{
Identification and Intensity of Food Insecurity and Coping Strategies of Rural Households: The Case of Gombora and Misha District, Hadiya Zone, Southern Ethiopia
}

\author{
Nuri Lefebo Toramo (PhD) \\ Assistant professor, Wachemo University, Ethiopia \\ Kacha Assefa (Ph.D) \\ Assistant professor, Wachemo University, Ethiopia
}

\begin{abstract}
A clear identification and understanding intensity of food insecurity and coping strategies of rural households helps policy makers and planners formulate new policies that enhance food security. Therefore, this study was conducted to identify major causes of food insecurity and coping strategies of rural households. In order to achieve these objectives biophysical; demographic and socio-economic data were collected from 150 randomly selected households in Gombora and Misha district, hadiya zone, southern Ethiopia.In addition, secondary data were collected from relevant organizations and pertinent documents. Descriptive statistics such as mean, standard deviation and percentages were used for analyzing the data. Moreover, t-test and $\chi^{2}-$ test were employed to describe characteristics of food secure and food insecure groups. The survey result shows that about $72 \%$ of sample farmers were food insecure A logistic regression model was fitted to analyze the potential variables affecting household food insecurity in the study area. Among 14 explanatory variables included in the logistic model, 9 of them were significant at less than $10 \%$ probability level. These were family size, number of oxen owned, use of chemical fertilizer, size of cultivated land, farm credit use, total annual income per adult equivalent, food consumption expenditure, livestock owned, and off-farm income per adult equivalent. The estimated model correctly predicted $92 \%$ of the sample cases, $81 \%$ food secure and $96 \%$ food insecure.
\end{abstract}

Keywords: food insecurity, coping strategies, logistic regression, Ethiopia.

DOI: $10.7176 / \mathrm{JESD} / 11-15-03$

Publication date:August $31^{\text {st }} 2020$

\section{INTRODUCTION}

Every man, woman and child has the inalienable right to be free from hunger and malnutrition in order to develop fully and maintain their physical and mental faculties. (United Nations, 1974, as cited by Maxwell, et al, 1992). Despite this legal commitment by the United Nations, it is estimated that over 100 million people in Africa are food-insecure, more than half of the continent's food-insecure people live in Ethiopia and six other countries: Chad, Zaire, Uganda, Mozambique, Zambia, and Somalia. Over $40 \%$ of the population in these countries is estimated to be food-insecure (World Bank, 1986, as cited by Sisay, 1995).

Until the late 1950's, Ethiopia had been self-sufficient in staple food and was classified as a net exporter of food grains. It was reported that the annual export of grain to the world market amounted to 150,000 tons in 1947/48 (Alemayehu, 1988, as cited by Tesfaye, 1995). However, since the early 1960s domestic food supply failed to meet the food requirements of the people. Since the beginning of the mid-1980s, food production has exhibited very low rate of growth (ibid). Total domestic food production increased only at 0.5 percent per annum; whereas per capita food production in the same period drastically dropped by 2.5 percent owing to rapid population growth (ibid).

The food self-sufficiency ratio, as measured by the percentage of food demand met by domestic production, has also declined following the decreasing trend in food production (Tesfaye, 1995). The ratio, which was 97 percent in 1980 declined to 88 percent in the 1980s (ibid). This trend, in combination with other factors, has threatened the food security status of the people of Ethiopia.

In Ethiopia 85 percent of the population is engaged in Agriculture (EEPRI,2002). The primary sector is the prime source of food supply, but is characterized by fragmented small farms operated by farming households. Moreover, farmers use animal-drawn implements and hand tools to cultivate the land. Ethiopian agriculture is mostly rain-fed. Due to changes in the rainfall pattern and other reasons the country has been facing persistent food shortages for more than 30 years and the recurring droughts coupled with decreasing farm size have made the situation worse (FSS, 2002). That is why both chronic and transitory problems of food insecurity are severe in Ethiopia. Each year more than four million people, particularly in the rural areas have the problem of getting enough food, and they need assistance (ibid). The household income consumption survey showed that in 1995/96 the incidence of poverty was on average 45 percent (GoE, 1994).

Consequently, Ethiopia became the largest recipient of food aid in Africa. Food aid delivered to Ethiopia 
between 1985 and 2000 amounted to around 10 million tonnes, equivalent to 10 percent of the annual national food grain supplies (Middlebrook, et al, 2001). In most cases the problem is not one of food availability, but decline in food entitlement. As a result, food aid does not provide a sustainable solution for tackling chronic foodinsecurity. Moreover, there is a danger that dependence upon food aid undermines efforts to develop an appropriate policy and institutional environment for long-term development and poverty reduction (ibid). These challenges need serious attention before they get worse.

In order to address these challenges, the Ethiopian Government issued a program document: 'Ethiopia's Food Security Strategy' in November 1996 and updated it in January 2002. The strategy document highlighted the elements of the Government's plan to address problems of food-insecurity in Ethiopia. The overall objective of the strategy is to raise the level of food self-reliance nationally and to ensure household food security in the longterm (Strategy Document, 2002). In addition, the Government of Ethiopia issued a development strategy called 'Agriculture Development Led Industry' (ADLI). ADLI identifies agriculture as the principal sector for achieving economic growth objectives. However, Middlebrook (2001), comments that a number of factors have constrained the effectiveness of the strategy in reducing poverty and food-insecurity. Some of them are: A heavy focus on domestic selfsufficiency, which even if attained, will not improve access to food by poorer income groups, overdependence on technological solutions to agricultural growth as epitomised by the supply-side approach of the new extension programme, limited purchasing power of the rural people and failure to promote non-agricultural employment in low potential areas.

The declining size of land holding can have serious implications in Ethiopia. Degradation and declining productivity of land, a static land tenure system and rapid population growth contributes negatively to the size of landholding of the rural households in Ethiopia in general and Gonbora and Misha district in particular (Desalegn 1998). Several studies indicate that these problems limit access to farmland for newly established households in the area (ibid). To some extent this is addressed by traditional coping mechanisms such us ploughing marginal lands, off-farm employment and migration. However, these copying mechanisms may not remain viable (ibid).

This situation is exacerbated by conflict and institutional environment, which provide limited opportunities for vulnerable groups to engage in agricultural production or otherwise secure access to food. Gonbora and Misha, one of the districts of Hadiya zone of Southern region, shares all the problems mentioned above and is identified as one of food-insecure areas of the country. The dependency ratio of the zone in terms of percentage is 97 , which means every hundred economically active age population has an extra of 97 persons to feed, cloth and educate (CSA, 1992).

In general, population growth is one of the major causes of fragmentation, fragmentation in turn brings about degradation, and degradation is the cause for declining of productivity of land, which in turn affects the overall agricultural production of the household. Decline in agricultural production will result in decline in income of the household, which ultimately result in decline in the status of household food security. Therefore, consideration of identification and intensity of food insecurity and coping strategies of rural households is important because it provides information that would enable to undertake effective measures with the aim of improving rural livelihoods in general and food security in particular.

\subsection{Statement of the Problem}

Poverty, inequality and food insecurity are the most crucial and persistent problems facing humanity. As the scale of human activities expands the capacity of eco-systems to regenerate the natural resource base becomes an increasingly binding constraint to further growth and development. With respect to agriculture, the combined effect of population growth on the developing countries, of increase per caput income of changes in dietary pattern linked inter alias to growing urbanization, will bring about sustainable increases in demand for food and other agricultural products (Kostas et al., 2001).

The environment is fragile in the study area without soil and water conservation measures one cannot practice successful farming activities in most parts of the district (Getachew 1991). Traditional farming practices over a long period of time with little or no soil conservation measures have severely eroded the fertility of the soil and have made agricultural output susceptible even to minor climatic changes (ibid).

As a result, the asset base of the transitorily food-insecure households is depleting gradually pushing these households deeper into chronically food-insecure category, thus creating a famine situation. If the number of hungry people continues to increase at the present rate, in a few years all the households in the district will be chronically food-insecure, leading to strong social and political repercussions. In addition, the study conducted by Getachew (1995) illustrated that 3-9 months' food requirement of the households' in Gonbora and Misha districts will met from sources other than own farm production. This showed that farmers could not produce enough for the entire household from the present holding. He maintained that under such circumstances, food-insecurity would occur all through the year and relief-food became necessary. This is a serious issue that need to be addressed. The food-aid delivered to the district and beneficiaries has been increasing since 1992 (ibid). This is not a healthy situation and it is a serious issue that need to be addressed. 
In addition, shortage of land for agricultural purposes, diminution of the size of holdings appeared to be one of the main constraints associated with land (Daniel and Wiebe,1998). Decrease in land size due to static land tenure system resulted in decrease in production which in turn resulted in decrease in availability and access to food for the household, hence, land tenure security and food security are highly correlated (ibid).

Over the last twenty years, land size per household was steadily decreasing in Eastern Hararghe in general and Gonbora and Misha districts in particular (Getachew, 1995). The household land size holding reached below minimum level that could not feed the growing household size. This has made farmers vulnerable to natural calamities, hazards, and little climatic changes. It also made the study area food deficit even in good years. The farmers could not produce food for the entire family enough for the whole year. Moreover, the recurrent drought worsened the situation and the area is identified as one of the food deficient districts of the country and more than $40 \%$ of the population is chronically food-insecure. The main causes of the household food insecurity in the study area are: shortages of rainfall and small size of holding (Getachew, 1991). The problems are persistent and need policy attention to bring about lasting solution. So far, no sustainable and concerted effort has been made to address these problems on sustained basis. Short-term solutions are sought to a problem, which is a permanent one and growing at alarming rate, wiping out asset base of farmers and leaving them vulnerable to simple environmental changes.

Keeping in view the above problems, issues and challenges, the study will attempts to answer the following key questions:

1. Who are food-secure and insecure households?

2. What is the existing land tenure system in the district?

3. What is the relationship between land size and food security?

4. What are the key issues and challenges related to land size and food security that need attention?

\subsection{Objectives of the Study}

\subsubsection{General objective}

The general objective of this study will be identification and intensity of food insecurity and coping strategies of rural households in Gombora district Hadiya zone, southern Ethiopia.

\subsubsection{Specific objectives will be:}

1. To characterize the land tenure system and household food security,

2. To analyse the influence of land size on household food security.

3. To identify factors that best discriminate food-secure households from food-insecure households

4. To indentify most effective food insecurity coping strategies of rural households

\section{LITERATURE REVIEW}

In the world of today, food insecurity is a widespread phenomenon despite the fact that food security is considered as a basic human right. As Walter rightly put it, human rights begin with breakfast. Food insecurity is seen as an evil experienced at an individual level. It is becoming the most critical issue in the developing world and most critical issue of the development agenda (Gezahen, Steven W.O and Eleni, 2003). Food insecurity is a major constraint to the development of many African, Caribbean and Pacific (ACP) countries. It is estimated that more than one-third of the population does not have access to proper or sufficient food for an active and healthy life.

\subsection{Concepts of Food Security}

Food insecurity is the lack of access to sufficient food, either chronically or transitorily, that leads to poor health, reduced energy, and other physical and physiological deterioration. Chronic food insecurity is due to the unavailability of food or lack, of resources to acquire it. Transitory food insecurity is a temporary decline in a household's food supply due to instability in food production, prices or market availability, or household incomes. Food security is sometimes equated with food self-sufficiency, either at household or national levels.

In the last two and a half decades, food security has become an important concept in development literature. The roots of the concern with the food security concept in recent years began with the world food crisis during 1972-74. Thus, the food insecurity problem in the 1970s was conceptualized as a supply problem without considering the ability of the population to access the food even if it was available. The approach to food security dramatically shifted in the 1980 s and since then the conceptualization of food security recognizes both the supply as well as, entitlement dimension of the food problem. Sen's concept of entitlement to food (Sen, 1981) contributed for the shift in the conceptualization of food security in the 1980s. Using the case of famine in Bangladesh and Ethiopia, Sen demonstrated the misguiding attitude of per capita food availability indicators in order to prevent famine. Thus, the entitlement approach was first proposed to explain the occurrence of famine, and "the ability of people to command food through legal means that is available in the society" (Sen, 1981). On the other hand, the theories concentrate on entitlement (protection failure) and market failure. Entitlement refers to peoples' acquirements and the resource through which society and political economy allows their access to food. Sen 
focuses on micro-level (household-level) food security, social relations and classes that bridge economists and political economists. Among other things, Sen's entitlement approach asserts that focusing on aggregate food availability is inadequate. Its influence has to be seen only as an element of a more complex entitlement process (Dreze, 1995).

The other dimension in the conceptualization of food security is the level of analysis or aggregation. Since the 1970s, the definitions and conceptualization of food security evolved in terms of level of analysis, that is, from the world to nation or from the nation to regions and from regions to households and individuals. With the shift of emphasis from supply to entitlement in the 1980s, Sen's entitlement concept and other studies have demonstrated the ambiguity of global, or national and regional levels of the aggregate measures of food security. However, lack of generally accepted standard measurements or indicators of food insecurity remain part of the ongoing debates in the food-security literature. There is no single measure of food security. The appropriate measure depends on the level of aggregation at which the problem is analyzed. The food security literature in the 1980s was able to combine the notions of poverty, under- nutrition and vulnerability in the definitions of food security (Maxwell and Frankenberger, 1992). As Maxwell et al. (1992) rightly put it "there is no single definition (though some definitions are more often cited than others), but rather complex weave of interrelated strands, which are adjusted to suit the needs and priorities of individual users" (ibid).

In the context of subsistence farmers' households, food security refers to the ability to establish access to productive resources such as land, livestock, agricultural inputs and family labor, combined to produce food or cash (Getachew, 1995). Consistent with this, Bonnard (1999) argues that there are three major components of food security: availability, access and utilization (Haddad, 1997; Kifle and Yoseph, 1999). Food availability refers to the need to produce sufficient food in a way that generates income for small-scale producers while not depleting the natural resource base, and the need to get this food into the market for sale at prices that consumers can afford (Haddad, 1997). According to Kfile and Yoseph (1999), availability is basically the household's capacity to produce the food it needs. Generally, however, definitions of food security have some common themes although they vary depending on the way the definitions are initially derived. In the majority of the food-security definitions, themes such as sufficiency, access, security and time are the key defining characteristics of the concept of food security. Three definitions of food security that were put forward by Edie (1986), Calkins (1986) and the World Bank (1986) will be briefly reviewed below.

Finally, the concept and definition of food security were developed and clearly expanded based on the growing hunger, food insecurity and malnutrition scenarios in developing countries. From the above definitions of food security, slight variations were observed. However, the overall basic principles and definitions of food security, that is, "availability and access" were stressed in the definitions cited above. Therefore, for the purpose of this study, the definition put forward by World Bank (1986) was taken as a working definition of food security and the household level is considered as the key unit of food security analysis.

\subsection{Sources of Food Insecurity}

Rural households faced a variety of risks, which may vary from natural to man made factors (Debebe, 1995). Drought (climate) could be considered as a major cause of famine. Hansen (1986) provided a purely scientific, meteorological definition of drought and a definition that relates drought to human activities. Devereux (1993) and Mesfin (1986) argue that one cannot completely ignore climate, by saying "climatic shocks are neither a necessary nor sufficient cause of famine." With widespread crop failures, natural or other disasters as well as the risk of fluctuation in production are some of the risk condition contributing to food entitlement failure. Moreover, variability in food supply, market and price variability, risks in employment and wages, and risks in health and morbidity, and conflict are also an increasingly common source of risk to food entitlements

\subsection{Food Security: Measurement and Indicators}

Measuring the required food for an active and healthy life and the degree of food security attained is a question to be addressed in a food security study. Given the multiple dimensions of food insecurity, there can be no single indicator for measuring it. For this purpose different indicators are needed to capture the various dimensions at the country, household and individual levels. At the national or regional level, food security can be measured in terms of food demand (requirement) and supply indicators. The supply of food at this stage may be from current production and stocks from previous production where as the need has to be determined on the bases of biological or nutritional requirement of a given society for a certain period of time usually a year or a day. Nutritional intake is also determined by physical exercises.

Food security indicators are classified into two main categories: process and outcome indicators. The process indicators provide estimates of food supply and food access situations. The outcome indicators serve as a proxy for food consumption (Frankenberger, 1992). Process indicators are used to measure the changing status of food security. They can also offer the type of information necessary to plan and adjust development efforts. Process indicators are further disaggregated into two groups: supply indicators and access indicators. Process indicators 
include indicators that reflect food supply. The most commonly used indicators of household food security are supply, food access and outcome indicators. These indicators embrace metrological data, information on natural resources, agricultural production data, marketing information, food balance sheet, sales of productive assets, diversification of income sources and household budget expenditure security (Frankenberger, 1992).

Accordingly, food balance sheet (i.e., sum of domestic food production, net import and stocks to the total population and considering nutritive value), rainfall and marketing data and anthropometrics measurements (revealing the state of under weight, stunting and wasting) are also used to measure food security. Specification of indicators of food security is particularly important to provide monitoring of early warning of food crises and the extent to which key sections of the population are under nourished (Eele, 1994, cited in Bezabih, 2000). Both process and outcome indicators of food security can be important when assessing food security, but access indicators measure that food access become apparent when governments and development agencies realize existence of household food insecurity and famine conditions are occurring despite the availability of food.

Outcome indicators, unlike the supply indicators, can be disaggregated at lower level. They include household budget and expenditure, subsistence potential, food consumption frequency, nutritional status, storage estimate and household perceptions of food insecurity. Some of the problems with outcome indicators like anthropometrics are their results may not exactly indicate the level of food crisis. It is because nutritional intake is affected by a number of factors such as health and sanitation. Food security at the household level is best measured by direct surveys of dietary intake in comparison with appropriate adequacy norms.

\subsection{Households Strategies of Coping with Food Insecurity.}

Coping strategies are the bundle of poor people's responses to declining food availability and entitlement in abnormal seasons or years (Davies, 2004). Farm households respond to the problems caused by seasonal and disaster (mainly drought) related food insecurity in different ways. Various coping mechanisms that are identified by different authors (e.g., Messer, 1989; Dagnew, 1994) can be put under three broad categories. These are production-based responses (expansion of production and improving productivity); market-based responses (food grain purchase through mainly sales of livestock) and nonmarket- based responses (including institutional and societal income transfer systems such as gift and relief food distribution).

Coping mechanisms used by farm households in rural Ethiopia include livestock sales, agricultural employment, certain types of off-farm employment and migration to other areas, requesting grain loans, sale of wood or charcoal, small scale trading, selling cow dung and crop residues, reduction of food consumption, consumption of meat from their livestock, consumption of wild plants, reliance on relief assistance, relying on remittances from relatives, selling of clothes, and dismantling of parts of their houses for sale. Some of them are likely to be implemented only after the possibilities of certain other options have been pursued (Cutler 1984; Dessalegn,1991). In addition, households who have diversified source of income are often able to cope with crisis than others (Yared, 1999).

All households are not equally vulnerable to food shortages and do not respond to it in the same way. Deprived households are more vulnerable to disasters than relatively better off households. The destitute are often forced to immediately collapse and get engaged in unusual and marginal kinds of economic activities (such as sales of grass, wood, leaves, and eating wild food and at the end migration). Since the country is dependent on agriculture, crop failure usually leads to household food deficit. The absence of off farm income opportunities, and delayed food aid assistance, leads to asset depletion and increasing levels of destitution at household level. As it was discussed before, farm households in different vulnerable areas of the country use different coping mechanisms against food insecurity.

\section{METHODOLOGY}

Description of the Study Area. This study was undertaken in one of the district of Hadiya Zone located in the southern Ethiopia.

Data Sources, Sampling and Data Collection: A two-stage random sampling procedure will be used to identify the households to be included in the study. However, because of three major reasons the sampling procedure and size of samples will be modified. These include: because of the difference between formerly traditionally categorized agro-ecological zone and the recent map of the woreda prepared by WFP (which shows only two agroecological zones while the former will be grouped it into three agro- ecological zones); The woreda PAs/ villages are grouped in to two based on NGO intervention and Non- NGO; The third one will be regarding the additional sample consideration because of the above two major reasons and from the project proposals of the Agri-service, other papers of the organization reviewed and discussion held with the regional programme officials, the researcher will come to know that the intention of the Agri-Service Ethiopia is to cover $60 \%$ of a development center and the remaining are expected to learn through high diffusion process. Considering these aspects, it will be assumed that the probability of getting a reasonable sample size of project participant would be high.

Moreover, technically the researcher prescribed to the concept, which states that stratification is not an 
essential feature of probability sampling, and two groups in the sample can easily be compared without prior stratification, provided that reasonable sample size is obtained.Finally, the sampling procedure will be changed in such a way that, the number of respondents from two groups (NGO and Non-NGO) will be 120 households selected randomly proportionally from each agro-ecological zone. On this basis, the 120 and 30 household heads will be selected

In this study, both primary and secondary data sources were used to gather necessary data regarding to assess the intensity of food insecurity and coping strategies. The data used for this study were collected from a sample through structured questionnaires, which were prepared for the study. Information pertaining to respondents, socioeconomic characteristics and institutional situations etc. were obtained directly through the interview, which was conducted at household level. Secondary data were obtained from published and unpublished documents of different organizations

Methods of Data Analysis: Descriptive statistics like means, frequencies, percentages, maximum, minimum, and range were used to describe the descriptive result while Logistic regression model were employed to identify the intensity of food insecurity and coping strategies.

Specification of the models: Following Pindyck and Rubinfeld (1981) the cumulative logistic probability function is specified as:

$$
\mathrm{P}_{\mathrm{i}}=\mathrm{F}\left(\mathrm{Z}_{\mathrm{i}}\right)=\mathrm{F}\left(\alpha+\sum_{i=1}^{m} B_{i} X_{i}\right)=\left(1 / 1+\mathrm{e}^{-\left(\alpha+\sum \beta_{\mathrm{i}} \mathrm{x}_{\mathrm{i}}\right)}\right)
$$

Where: $P_{i}$ the probability that a household is being food secure given $X_{i}$ and, given explanatory variables $\left(X_{i}\right)$; e represents the base of natural logarithms (2.718); $\mathrm{X}_{\mathrm{i}} \quad$ represents the explanatory variables; $\mathrm{m}_{\mathrm{i}}$ represents the number of explanatory variables, $\quad \mathrm{i}=1,2,3 \ldots, \mathrm{m}$, and $\alpha$ and $\beta_{\mathrm{i}}$ are parameters to be estimated.

Coefficient interpretation will be understandable if the logistic model once written in terms of the odds and log of odds (Hosmer and Lemeshow, 1989). The odds ratio is simply the ratio of the probability of being food secure $\left(\mathrm{P}_{\mathrm{i}}\right)$ to the probability that he/she would be food insecure $\left(1-\mathrm{P}_{\mathrm{i}}\right)$. But $\mathrm{P}_{\mathrm{i}}$ is non-linear not only in $\mathrm{X}_{\mathrm{i}}$ but also in $\alpha_{\mathrm{i}}$ and $\beta_{\mathrm{i}}$ which creates an estimation problem. So, we cannot use the familiar OLS procedure to estimate the parameters.

But $1-\mathrm{P}_{\mathrm{i}}=\frac{1}{1+e^{z i}}$

Therefore, the odds ratio becomes,

$$
\frac{p_{i}}{1-p_{i}}=\frac{1+e^{z_{i}}}{1+e^{-z_{i}}}=e^{z_{i}}
$$

Therefore, to get linearity, we take the natural logarithms of odds ratio equation (4), which results in the logit model as indicated below:

$\mathrm{Zi}=\operatorname{Ln}\left(\frac{p_{i}}{1-p_{i}}\right)=\alpha+\beta_{1} \mathrm{X}_{1}+\beta_{2} \mathrm{X}_{2}+\ldots+\beta_{\mathrm{m}} \mathrm{X}_{\mathrm{m}}$

As $\mathrm{P}$ goes from $\mathrm{o}$ to 1 , the logit goes from $-\infty$ to $\infty$. That is, although the probabilities lie between 0 and 1 , the logits are not so bounded (Gujarati, 1995).

If the disturbance term $U_{i}$ is taken into account, the logit model becomes,

$$
\mathrm{Z}_{i}=\alpha+\sum_{i=1}^{m} \beta_{i} \chi_{i}+u_{i}
$$

Definitions of Variables and Working Hypothesis

Dependent variable of the logic model (DEPENT) $\mathbf{Y}_{\mathrm{i}}$ : Food security at household level is best measured by direct surveys of income, expenditure, consumption, and comparing it with the adequacy norm (minimum subsistence requirement). Specifically, average income and expenses are commonly used to compute proxy indicators of food security. In this study, the total household expenditure per adult equivalent was taken to compute proxy indicator of food security. The selection of this indicator as dependent variable in this study was due to the fact that theoretical arguments support it since consumers normally understate their incomes than their total expenditure.

As it may be recalled from the theoretical framework of economic theory, traditionally a consumer maximizes his utility subject to his budget constraint, i.e., his total expenditure; so if expenditures is assumed to be made direct for consumption, they contribute directly to utility while income contributed indirectly. The actual household expenditure in this study is considered as the sum of the total annual expenditure incurred by the household for consumption (including own produce) as well as non-consumption. It includes the sum of own produce consumed 
(cereals, pulses, oil seeds, vegetables, livestock, and livestock products), expenses on clothing, medical, education, taxes, social obligations, household utensils, transportation costs and marketing costs).

This actual expenditure per adult equivalent per annum was calculated by summing up all the required expenditure components and dividing it by the total adult equivalents (AE) of the household. On the other hand, subsistence level of household expenditure or minimum level of income, which should at least meet the needs of adult person, was computed based on the amount of food required. The value of minimum amount of energy ( 2100 $\mathrm{kcal} / \mathrm{AE} /$ day or $225 \mathrm{~kg}$ cereals/AE/year) at an average price of grain in the local market plus the sum of estimated minimum amount of money needed to cover the above mentioned expenses per AE per annum were used as a threshold beyond which the household is said to be food secure. The sum of Birr 650 was considered as the minimum subsistence expense (threshold) beyond which the household is said to be food-secured in the study area. The household food security status, which is, the dependent variable for the logit analysis had a dichotomous value representing the status of household food security. It was represented in the model by a value of 1 if a given household belongs to food secure and 0 for food insecure households.

The explanatory variables: Based on the literatures reviewed and discussion held with stakeholders, the explanatory variables selected for this study were broadly categorized under socioeconomic, institutional and natural factors. In what follows, a brief explanation of the explanatory variables selected for this study and their likely influence on the food security is presented below.

Age of household head (AGEHH): Age matters in any occupation. Rural households mostly devote their lifetime or base their livelihoods on agriculture. It was argued as the age of the household head increases the farmer acquires more knowledge and experiences with possible negative impact on food insecurity. In other ways, it was expected that younger farmers are more likely to be food insecure than the older farmers that the older ones due to better possession of resources accumulation. In light of this, it is hypothesized that ages of the household heads and food insecurity are negatively correlated.

Family size (FAMILYSZ): It is an important variable, which determines the household food security status in the study area. The expectation is that the household with large number of children or economically dependent family members will face food insecurity because of high dependency burden. The existence of large number of children under age of 15 and old age of 60 and above in the family could affect the food security status of the household. That means, the working age population (i.e., 15-60 years) supports not only themselves, but also additional dependent persons in the family. Thus, it is hypothesized that the family with relatively large number of dependent family members (high dependency ratio) negatively affects household food security status.

Education level of household head (EDUC): This is a dummy variable, which takes a value 1 if the household is literate and 0 otherwise. Educated farmers are expected to have exposure to external environment, to be acquainted with agricultural technologies, too frequently meet DA's and get written agricultural materials, etc. Therefore, an educated farmer would be positive relation to food security.

Farm size (FARMSZ): This is the total farm size cultivated by the household given in hectare. Total cultivated land owned by household is important resource for food production. Hence, it is expected to be associated with food security status. It was hypothesized that farmers who have larger farm landholding would have less probability to be food insecure.

Soil fertility problem (SFP): It is a dummy variable taking value 1, if the farm household faces problem of soil fertility and 0 otherwise. Soil fertility problem is one of the physical factors affecting crop production. It is hypothesized that farm households who faced soil fertility problem are more likely to be food insecure than those who do not have the problem.

Number of oxen owned(OX): Oxen are the most important means of land cultivation and basic factor of production. Households who own more oxen have better chance to escape food shortages since the possession of oxen allows effective utilization of the land and labour resources of the household. The number of oxen available to the household was therefore, hypothesized to increase the probability of the household being food secure.

Off-farm income (OffINC): When crop production and income earned from sales of livestock and livestock products become inadequate to subsist the farming households of the study area they often depend on external or other source of income to purchase food and farm inputs. So income earned from off farm activities is an important variable, which determines household food security in the study area. In this regard, households engaged in offfarm activities are better endowed with additional income and less likely to be food insecure. Therefore, off-farm income per AE is expected to positively associate with household food security status.

Total livestock ownership (TLU): The livestock holding of the household was measured in terms of livestock units. Livestock are the farmers' important sources of wealth as farmers accumulate wealth in terms of livestock. Households who possess large livestock size are expected to be less vulnerable to food insecurity. Since households with larger livestock size produce more milk, milk products and meat for direct consumption owners could be more food secured. Besides, the contribution of livestock to food security includes the draft power, manure and income from sales of livestock and livestock products, which are often used for purchase of food grains during times of food shortage. Livestock sale is also used as the major coping strategy during famine and seasonal food 
shortage. Hence, it is logical to expect that a higher value of TLU is associated with the probability of being food secure.

Chemical fertilizer uses: It is dummy variable taking value 1 , if the farmers used chemical fertilizers and 0 otherwise. The use of fertilizer has been perceived as improving yield per unit area. Hence, it was hypothesized that the households using fertilizer are expected to be more food secure than the non-users. In the group discussions with farmers indicated that fertilizer application is economical in increasing crop yield.

Irrigation: It is a dummy variable in the model taking a value of 1 if the household uses irrigation, 0 otherwise. In areas where agriculture is the prime source of livelihood of the society, soil moisture is very crucial. Even if the climatic condition in a given area is conducive, then it would be far better to be supplemented with irrigation so that increased output could be attained. However, in the study area drought, erratic rainfall patterns and other factors limit the output per hectare, and made it one of the food insecure districts in the region. Hence, it was hypothesized that the use of irrigation and food insecurity are negatively related.

Use of improved seed: This is also a dummy variable taking value of 1 , if the farmers used improved seeds and 0 otherwise. Moisture stress resistant varieties contribute one of the modern agricultural inputs that can withstand drought and erratic rain distribution. It augments agricultural productivity by boosting overall production, which in turn contributes to attaining households' food security. In the study area the household who used improved seeds have a chance of getting high production as a result they become food secure than the non-user group. Hence, it was hypothesized that using improved seeds and food security are positively related. There is also risk involved in use of improved technologies under areas such as Gombora and Misha districts due to limited supply and high prices.

Insect and pest infestation: It is a dummy variable in the model taking the value 1 , if the households faced insect and pest infestation and 0 otherwise. It is an important biological factor limiting crop production and causing food shortage in study area. It was assumed that farmers with problem of pest infestation are more likely to be food insecure than those who do not have this problem. Thus, pests and insects' infestation is negatively correlated with food security status.

Pattern of food consumption: The pattern of consumption of food includes own production consumed, which forms the major part of family's consumption, Therefore, it is hypothesized that the proportion of household expenditure equivalent on own food is positively correlated with the household food security status.

Farm credit received: It is a dummy variable in the model taking value 1 , if farmers got farm credit and 0 otherwise. Credit is an important source of earning future income. Those households who received farm credit have possibility to invest in farming activities, which is important component in small farm development programs. In the study area, farm households who have easy access to credit at times of peak season of cultivation avail it and increase their production. Hence, it was expected that credit in general have a positive impact on food security status.

Food aid: The study area frequently faces food shortage and its productive resources particularly, land is less productive. Therefore, the frequency of food aid distribution and its amount obtained by farm households is one indicator of food insecurity. Hence, since Gombora and Misha is one of the drought affected district, it is expected that farm households who have been receiving food aid more likely cope with food insecurity.

Distance from market center: Access to market and other public infrastructure may create opportunities of more income by providing non-farm employment and access to transportation facilities. It is hypothesized, that households who have good accessibility to market center have better chance to improve farm household food security status than who do not have a proximity to market centers. Hence, distance from market center is negatively related to food security.

\section{RESULTS AND DISCUSSION}

\subsection{Results of Descriptive Statistics Analysis.}

The descriptive statistics analysis made use of tools such as mean, percentage, standard deviation and frequency distribution. In addition, T-test and Chi-square test statistics were employed to compare food secure and food insecure groups with respect to some explanatory variables. In this study detailed information on households' food security status was discussed based on World Bank's (1986) definition of food security, which is "access by all people at all times to enough food for active and healthy life". In this study, food security is defined as the extent to which a total household expenditure per AE meets its subsistence requirement. Total expenditure consists of expenditures including own produce, stimulants, clothing and footwear, household equipment, social obligation and various services.

Out of the total 150 interviewed households $108(72 \%)$ were food insecure, and the remaining $42(28 \%)$ were food secure. The average age of the respondents was 50 years with the minimum and maximum ages of 22 and 83 years, respectively. The average age of food secured household heads was 52 years, while that of food insecure was 49 years with mean difference significant at $1 \%$ level. On the other hand, the average family size of the sample households was 5.3; higher than the national average of 5 persons (CSA, 1994). The largest family size was 14 
and the smallest was 1 . The average family size of food secure was 4.4 , while that of food insecure was 5.8 with no significant difference between means of the two groups.

The survey results also revealed that 53 percent of the sample household heads were illiterate, whereas 47 percent of the house holds heads were literate (Table 3). Of the total sample respondents, 47 percent of the food secures and 55 percent of food insecure were illiterate respectively with mean difference significant at $1 \%$ level of the two groups. and credit users in terms of their literacy level. The average size of own cultivated land was nearly 1.49 ha, the minimum and the maximum being 0.25 and 5 ha, respectively. Food secured respondents cultivated on average larger area of land (1.51ha) than food insecure respondents (1.07ha). The mean difference was significant at $1 \%$ level. The results of the survey also indicate that the average gross income were 2123 for food secured respodents and 1321 for food insecure respondents respectively. The differences between the two groups, was significant at $1 \%$ probability level.

Table2. Socio-economic and institutional characteristics of the households (continues variables)

\begin{tabular}{|c|c|c|c|c|c|c|c|}
\hline \multirow[t]{2}{*}{ Characteristics } & \multicolumn{2}{|c|}{$\begin{array}{l}\text { Food secure } \\
(\mathrm{N}=42)\end{array}$} & \multicolumn{2}{|c|}{$\begin{array}{l}\text { Food insecure } \\
(\mathrm{N}=108)\end{array}$} & \multirow[t]{2}{*}{$\mathrm{T}$ - value } & \multicolumn{2}{|c|}{$\begin{array}{l}\text { Total Sample } \\
(\mathrm{N}=150)\end{array}$} \\
\hline & Mean & St.dev & Mean & St.dev & & Mean & St. dev \\
\hline Age & 52 & 13 & 49.0 & 14.04 & $2.881^{* * *}$ & 50 & 13.02 \\
\hline Family Size & 4.4 & 2.26 & 5.8 & 2.15 & 0.240 & 5.3 & 2.13 \\
\hline Total land holding & 1.52 & 0.95 & 1.07 & 0.95 & $4.471 * * *$ & 1.48 & 0.84 \\
\hline Total live stocks in TLU & 3.71 & 4.27 & 2.12 & 2.59 & $2.431 * *$ & 3.78 & 4.12 \\
\hline Gross farm income & 2125 & 1323 & 1455 & 1243 & $2.81^{* * *}$ & 1825 & 1523 \\
\hline Amount of money spent & 40.55 & 244.70 & 86.76 & 177.23 & 0.594 & 64.81 & 234.91 \\
\hline $\begin{array}{l}\text { Amount of Money } \\
\text { Borrowed }\end{array}$ & 426.90 & 369.60 & 321.90 & 256.38 & 1.554 & 404.17 & 350.19 \\
\hline DA contact days/months & 1.86 & 1.46 & 0.97 & 1.36 & $2.611 * *$ & 1.52 & 1.46 \\
\hline Experience in agri. ext & 2.99 & 1.82 & 2.00 & 0.25 & $3.122 * * *$ & 2.74 & 1.66 \\
\hline
\end{tabular}

Source. Computed from the field survey data

$* * *$ and $* *$ represent level of significant at $1 \%$ and $5 \%$ level respectively.

Farmers in the study area undertake both crop and livestock production activities. Though livestock holding size varied among the sample farmers, 84.75 percent of the total respondents owned livestock. Livestock are kept for various economic and social reasons in the study area. The major economic reasons include provision or supply of draught power, generation of cash income, food and animal dung (as an organic fertilizer and fuel). Based on Storck et al. (1991) standard conversion factors, the livestock population number was converted into Tropical Livestock Unit (TLU), so as to facilitate comparison between the two groups. On the average, a household had 3.78 TLU with standard deviation of 4.12 (Table 3 ). The minimum number of livestock kept was 1 whereas the maximum was 35.5 TLU. Food secured respondents owned a larger number of livestock (on average $3.71 \mathrm{TLU}$ ) compared to the food insecure respondents (on average $2.12 \mathrm{TLU}$ ) with mean difference significant at 5\% significant level. The implication is that food secure respondents have more access to financial capital by selling their livestock to recover their loan (Table 2). Experience in agricultural extension package varied among the sample from minimum value of one-year experience to a maximum of 10 years experience. Food secure respondents participated on average for higher number of years (2.99) as compared to the food insecure respondents who participated on average for 2 years (Table 2). The mean difference between the two groups was significant at $1 \%$ level of significance. That is, farmers experience in agricultural extension services has significant role in food security. The results of the survey also indicate that 76.40 percent of the respondents had extension contact, while 23.60 percent did not have any contact with extension agents. An average number of extension contact days were 1.86 for food secure respondents and 0.97 for food insecure respondents, respectively. The differences between the two groups, was significant at $5 \%$ probability level. That is, respondents who had frequent contacts with development agents generate more production as compared to those who had no or few contacts (Table 2). 
Table 3. Socio-economic and institutional characteristics of farmrs (discrete variables)

\begin{tabular}{|c|c|c|c|c|c|c|c|}
\hline & \multicolumn{2}{|c|}{ Food secure } & \multicolumn{2}{|c|}{ Food insecure } & \multirow{2}{*}{$\chi^{2}$-value } & \multicolumn{2}{|c|}{ Total } \\
\hline & No. & Percent & No. & Percent & & No. & Percent \\
\hline Illiterate & 20 & 47 & 60 & 55 & $5.156 * * *$ & 79 & 53 \\
\hline Literate & 22 & 53 & 48 & 45 & & 71 & 47 \\
\hline Access to credit Yes & 75 & 88 & 22 & 47 & $7.480 * * *$ & 96 & 82 \\
\hline No & 10 & 12 & 11 & 53 & & 22 & 18 \\
\hline Income off-farm Yes & 27 & 32 & 5 & 14 & $3.757^{*}$ & 34 & 28 \\
\hline No & 58 & 68 & 28 & 86 & & 84 & 72 \\
\hline Saving Money Yes & 8 & 7 & 0 & 0.00 & 2.814 & 9 & 5 \\
\hline No & 77 & 93 & 33 & 100.00 & & 109 & 95 \\
\hline Purpose of borrowing & & & & & 0.165 & & \\
\hline For agri. Input purchasing & 49 & 58 & 18 & 56 & & 67 & 57 \\
\hline For other purposes & 37 & 42 & 15 & 44 & & 51 & 44 \\
\hline
\end{tabular}

Source. Computed from the field survey data

*** and * Represents significant at $1 \%$ and $10 \%$ level

The sample farmers were asked about their access to credit. Out of the total respondents, 88 percent of the food secures respondents and 47 percent of food insecure respondents replied that they have benefited from the credit service (Table 3). The difference in credit benefits was significant between the two categories.

\subsection{Results of the Econometric Model:}

Factors influencing farm households' food security: To study factors influencing farm households' food security, data gathered from 150 farmers were subjected to logistic regression analysis. The statistical software used for analyzing the data was stata 11 for windows. Prior to running the logistic regression model, both the continuous and discrete explanatory variables were checked and no problem for the existence of multi-collinearity.

A logistic regression model was fitted to analyze the potential variables affecting household food insecurity in the study area. Among 13 explanatory variables included in the logistic model, 9 of them were significant at less than $10 \%$ probability level. These were family size, number of oxen owned, use of chemical fertilizer, size of cultivated land, farm credit use, total annual income per adult equivalent, food consumption expenditure, livestock owned, and off-farm income per adult equivalent. The estimated model correctly predicted $92 \%$ of the sample cases, $81 \%$ food secure and $96 \%$ food insecure.

Family Size: among the important demographic variables, family size is to be highly significant in determining the probability of farm household's food security status in Gombora and misha districts. This variable is negatively associated with the food security status and significant at probability level of $1 \%$. This negative relationship indicates that odds ratio in favor of the probability of being food secure decreases as family size increases. If all other things are held constant, the odds ratio of 0.55 for family size implies that, the odds ratio in favor of being food secure decreased by a factor of 0.55 as family size increase by one person. The farm households with large family size, having children of non-productive age, could face the probability of food insecurity because of high dependency ratio than farm households with small family size. Therefore, this agrees' with the hypothesis that family size with high dependency ratio have role to play in affecting the probability of households food security status.

Number of Oxen Owned: Oxen are among the most important factors of production and hence determine household food security status. This variable is significant at a probability of $10 \%$ and has positive association with household food security. As hypothesized, this variable affects households food security. The more the number of oxen available to households the larger is the probability of being food secure. The positive sign of this variable indicates the contribution of this resource towards ensuring food security. The interpretation of the result shows that if other things are held constant, the odds ratio in favor of the probability of food security increases by a factor of 2.19 as the farm household's oxen holding increases by one.

Size of Cultivated Land: Size of cultivated land, which is significant at $10 \%$ probability level, has positive influence on the probability of farm household's food security in the study area. It implies that the probability of being food secure increases with cultivated farm size. This agree with the hypothesis that farmers who have larger farm land holding would be less food insecure than those with smaller land size, due to the fact that, larger farmers are associated with higher possibility to produce more food. With greater wealth and income which increases availability of capital that could increase the probability of investment in purchase of farm inputs which increases food production and hence ensuring food security of farm households. The odds ratio of 2.17 for the total cultivated farm size implies that other things kept constant, the odds ratio in favor of being food secure increases by a factor of 2.17 as the total cultivated farm size increases by one hectare.

Livestock Size: Livestock are important source of income, food and draft power for crop cultivation. Livestock 
size is positively and significantly associated with the probability of being food secure in the study area. This indicates that households with more livestock produce more milk, milk products and meat for direct consumption and owners could be more food secured. Besides, this enables the farm households to have better chance to earn more income from livestock production which enables them by increasing purchasing power of food during food shortage and could invest in purchasing of farm inputs that increase food production, and able in ensuring household food security. Hence, this empirical finding support that larger livestock holding is important source of income in explaining the probability of being food secure in the Gombora and misha Districts. The result indicates that, other things held constant, the odds ratio in favor of being food secure increases by a factor of 1.3 as the total livestock holding increase by one TLU.

Farm Credit Use: Credit is important source of investment on activities that generate income for farm households. The households can purchase agricultural inputs (improved seed, fertilizer, etc.) and livestock for resale after fattening. In Gombora and misha Districts, farm households who have access to credit could increase their production to escape food shortage. The logit model analysis revealed that credit has a significant positive association with food security status (at a probability level of 1\%). This is in agreement with the prior expectations about the impact of the differential access to credit service. This is because farm households who have the opportunity of accessing farm credit would build their capacity to produce more through purchasing of agricultural inputs. The households with more access to farm credit have possibility to reduce the probability of being vulnerable to food insecurity. The odds ratio in favor of food security increases; other things remain constant, by a factor of 1.66 as farm households get access to farm credit.

Use of Chemical Fertilizer: This variable has positive influence on the probability of food security situation, which is significant at 5\% level. This means that those farmers who have access to fertilizer use are more likely to be food secure than those who have no access to fertilizer use. The result indicates that, other factor kept constant, the odds ratio in favor of being food secure increases by a factor of 2.63 as a farm households fertilizer use increases by one unit.

Food Consumption Pattern: This variable indicates the households' pattern of consumption, which is expressed in terms of own production consumed. It represents the major parts of family's consumption defined in terms of value of food produced in the total expenditure (FNU/MoPED, 1992). This variable has positive sign of influence on the probability of being food secure and highly significant (at $1 \%$ probability level). The odds ratio in favor of the probability of food secure increases by a factor of 1.04 as the value of own food increases by one Birr.

Off-Farm Income: This variable represents the amount of income earned in cash or in kind, during the year. In the areas like Gombora and misha Districts, where the farmers face crop failure and sales of livestock and livestock product is inadequate, income earned from off-farm activities is an important means of acquiring food. Accordingly, in the study area, the success of farm households and their family members in coping with food insecurity is highly determined by their ability to get access to off-farm job opportunities. The result suggests that households engaged in off-farm activities are endowed with additional income and less likely to be food insecure. Consistent with the hypothesis, off-farm income is positively and significantly associated with farm households' food security status (at probability level of 10\%). The probabilities of farm households to be food secure increases by a factor of 1.00 as the farm households obtain one more unit of off-farm income per adult equivalent. The econometric result gives important clues regarding variables, which should be considered and given emphasis during interventions in order to overcome the problem of food insecurity in the study area (see Table 4).

Table4: Maximum likelihood estimates of logit model

\begin{tabular}{|c|c|c|c|c|}
\hline Explanatory variable & Estimated Coeffi. & Odds ratio & Wald statistics & Significance level \\
\hline Constant & -0.7444 & & 4.780 & 0.423 \\
\hline FAMILYSZ & $-0.5905^{* * *}$ & 0.5540 & 0.347 & 0.006 \\
\hline AGEHH & 0.0227 & 1.0229 & 0.428 & 0.103 \\
\hline Fertility problem & 0.7280 & 2.070 & 3.116 & 0.116 \\
\hline FARMSZ & $0.7766^{*}$ & 2.1741 & 3.004 & 0.059 \\
\hline Farm credit & $0.509^{* * *}$ & 1.6646 & 4.875 & 0.001 \\
\hline Total annual income & $0.0029^{* *}$ & 1.0029 & 8.834 & 0.0190 \\
\hline OXNO & $0.7862^{*}$ & 2.1950 & 0.471 & 0.0731 \\
\hline OffINC & $0.001^{* * *}$ & 1.001 & 4.068 & 0.001 \\
\hline Insect and pest problem & -0.567 & 0.5667 & 15.030 & 0.2402 \\
\hline Fertilizer use & $0.966^{* *}$ & 2.6270 & 19.972 & 0.028 \\
\hline Distance to market & -0.1566 & 0.8550 & 12.25 & 0.202 \\
\hline Food consumption pattern & $0.0349^{* * *}$ & 1.0356 & 1.032 & 0.007 \\
\hline TLU & $0.2963^{* * *}$ & 1.3445 & 2.077 & 0.001 \\
\hline $\begin{array}{l}2 \text { Log Likelihood } 143.21 \\
\text { Specificity }^{3} 78.6\end{array}$ & Model Chi-Square & $358^{* * *} \mathrm{Col}$ & S & 82.8 , Sensitivity \\
\hline
\end{tabular}


Coping Strategies:

Types of coping strategies and proportion of farmers practicing them (\%)

\begin{tabular}{|c|c|c|c|}
\hline Strategies Practiced by Farmers & $\begin{array}{l}\text { Food Secure } \\
(\mathrm{N}=42)\end{array}$ & $\begin{array}{l}\text { Food Insecure } \\
(\mathrm{N}=108)\end{array}$ & All C $(\mathrm{N}=150)$ cases \\
\hline 1.Purchasing grains & 26 & 43 & 38 \\
\hline 2.Borrowing cash or grains from others & 48 & 60 & 56 \\
\hline 3.Sales of animals to meet purchase of grain & 48 & 46 & 47 \\
\hline 4.Reducing number and size of meal & 7 & 53 & 40 \\
\hline 5.Collecting and eating wild food & 2 & 4 & 3 \\
\hline 6.Receiving relief food aid & 7 & 30 & 23 \\
\hline 7.Involve in off-farm and on farm job & 43 & 56 & 52 \\
\hline 8.Sales of fire wood and charcoal & 14 & 20 & 19 \\
\hline 9.Temporary migration to other area & 2 & 5 & 4 \\
\hline 10.Sales of key productive assets & 2 & 1 & 1 \\
\hline 11.Receiving gifts and remittances & 2 & 5 & 4 \\
\hline 12.Rent out land & 5 & 14 & 11 \\
\hline 13.Changing planting and cropping pattern & - & 4 & 3 \\
\hline
\end{tabular}

Source Own Survey (2004)

The survey results further revealed that food insecure households in the study area practiced sales of fire wood, cow dung and charcoal; rented out farm land; received gifts and remittances; changed cropping and planting pattern, sold productive assets as coping strategies. These categories were reported and practiced as a last resort by fewer sample respondents. The analyses of the coping mechanism of the sample farmers have shown that, coping mechanisms have different patterns. All farmers were not equally vulnerable to drought or food insecurity; they responded in different ways. Some households implement some coping strategies after all other options have been pursued and exhausted. As the food crisis persist, households are increasingly forced into a greater commitment of resources, just as the household exhaust the strategies that are available in the early stages of food crisis, they begin to dispose key productive assets such as draft oxen and rent out land. Other households (especially those who are easily vulnerable) often collapse immediately and thus engage in unusual activities such sales fuel wood and cow dung. Accordingly, among the sample households $1 \%$ of them (2\% food secured and $1 \%$ of food insecure households) sold key productive assets as coping mechanism for food insecurity.

On the other hand, about $5 \%$ of the food secure and 14\% of the food insecure sample households rented out their land as a coping mechanism in the study area. As drought and crisis persist in the area finally they decide to out migrate to cope with food supply shortfall. About $4 \%$ of all cases, $2 \%$ of the food secure and $5 \%$ of the food insecure sample households reported migration within their own areas to their relatives (particularly during months of July and August). With respect to the period of severe food shortage that the farm households practice these coping mechanisms, more than $87 \%$ of the households encountered severe food shortages during the months of July, August and September. In the study area almost all households face severe food shortage during August. As observed through group discussions, the farm households in the lowland ecological zone face severe food shortage more frequently than those in the mid highlands. With increasing vulnerability, farmers shift to the consumption of the cheapest and less quality of food. November, December and January, are the months when the majority of the respondents households do not face any kind of food shortage. In general, the proportion of households with local coping strategies implies the extent to which most of the Gombora and misha district's farmers are vulnerable and how food insecurity is serious. Hence, factors like poor marketing infrastructure lack of off-farm job opportunities, and lack of credit facilities aggravated food insecurity and made households more vulnerable.

\section{CONCLUSIONS AND POLICY IMPLICATIONS}

Gombora and misha Districts is one of chronically food insecure and vulnerable district in the hadiya zone southern Ethiopia. The area is designated as famine prone zone. The largest portion of thedistricts $(60 \%)$ experiences frequent crop failure and usually is vulnerable to food shortage.

Drought induced food insecurity has been recurrent phenomenon exacerbating the vulnerability of the resource poor farming households in the district. The major objectives of the study were to assess the major causes of food insecurity and to identify local coping strategies at household level and to identify policy options in the Gombora and misha districts in the Region.

The survey result shows that about $72 \%$ of sample farmers were food insecure A logistic regression model was fitted to analyze the potential variables affecting household food insecurity in the study area. Among 14 explanatory variables included in the logistic model, 9 of them were significant at less than $10 \%$ probability level. These were family size, number of oxen owned, use of chemical fertilizer, size of cultivated land, farm credit use, total annual income per adult equivalent, food consumption expenditure, livestock owned, and off-farm income per adult equivalent. The coping strategies and factors affecting the food security status give clue about policy 
options regarding interventions to reduce household's vulnerability to food insecurity

\section{REFERENCES}

Alamgir, M., and P. Arora, (1991) Providing Food Security for all. Published for the Ayalneh Bogale, (2002). Land Degradation, Impoverishment and Livelihood Strategies of Rural Households in Ethiopia: Farmers' perceptions and policy Implication. Vol.8. Shaker

Bazabih Emana, (2000). The Role of New Varieties and Chemical Fertilizer under Risk: The Case of Small holders in Eastern Oromia, Ethiopia. Ph.D dissertation. University of Hanover, Shaker Verlug, Germany.

Central Static Authority (CSA), (2007). Demographic and Health Survey Report. Addis Ababa, Ethiopia.

Maxwell, S., (1996). Measuring Food Insecurity: The Frequency and Severity of Coping Strategies. Food Policy 21(33): 291-303

Tekolla, Y., (1990). The African food Crisis. Food Crisis in Africa: Policy and management issues, edited by Eshtu Chole. New Delhi: African Association for Public Administration and Management.

Tweeten and Donald, (1997). Promoting Third-World Development and Food security.

Green wood publishing Group. United States of America

Toulmin, C., (1986). Access to food, dry season Strategies and household Size amongst the Bambara of Central Mali. IDS Bulletin 17, no. 3: 58-66.

Transitional Government of Ethiopia (TGE)/UNDP, 1993. Food production, food Security and nutrition. Addis Ababa: National program First Draft

Von Braun, J.; Bouis, H.; Kumar, S. and R. pandya- Lorch, (1992). Improving Food Security of the poor: Concept, Policy, and programs. International Food Policy Research Institute.

Washington, D.C, U.S.A.

Watt, M., (1983). Silent Violence: Food, Famine and Peasantry in Northern Nigeria. Brkeley, CA, USA: University of California Press

Webb, P., (1992). Famine in Ethiopia: Policy implication of the Coping failure at national and household levels. Research Report 92. Washington D.C.: International Food Policy Research Institute.

Webb, P.; Braun, J. and Yohannos,( 1991). Famine in Ethiopia: Policy Implication Coping Failure at National and Household Levels. Washington D.C. International Food Policy Research Institute. .

World Bank, (2009). Poverty and Hunger: Issues and Options in Developing Countries. A World Bank Policy Study, Washington D.C.

World Bank,(2010). Development and the Environment. World Development Report, World Development Indicators.

Yared Amare, (2008). Household Resources, Strategies and food security in Ethiopia. A Study of Amhara households in Wogda, Northern Showa. The Department of Sociology and social Administration, AAU Press, Ethiopia. 